Vidyodaya J., of Sci., (1992) Vol. 4, No. 1. pp: $201-208$

\title{
MINERAL NUTRITION OF Cymbopogon nardus (L) Rendle: PART I. EFFECTS OF MAGNESIUM AND PHOSPHORUS NUTRITION ON GROWTH AND THE YIELD OF ESSENTIAL OIL
}

\section{S. S. Ranaweera* and W. P. Thilakaratie}

Department of Botany, University of Sri Jayewardenepura, Nugegoda, Sri Lanka.

Received on : $26-06-1992$

Accepted on : $01-03-1992$

\begin{abstract}
A greenhouse pot experiment with thirteen treatments of fertilizers was conducted to examine the effects of phosphorus and magnesium on the growth of Cymbopogon nardus (L) Rendle (Ceylon citronella) and the yield of its essential oil. Phosphorus nutrition enhanced the tiller production, dry matter accumulation and the yield of essential oil. Magnesium in combination with phosphorus increased the yields of dry matter and the essential oil. Magnesium facilitated the uptake of phosphorus. High correlations were observed between leaf phosphorus content and the essential oil yield $(r=+0.7)$ and the number of tillers per slip $(r=+0.66)$. The essential oil yield correlated with the number of tillers $(r=+0.91)$ and the dry matter yield $(r=+0.89)$.
\end{abstract}

Key Words: Cymbopogon nardus, Magnesium and phosphorus nutrition, Growth, Essential oil yield, Leaf phosphorus

\section{Introduction}

Two closely related citronella species are cultivated, yielding essential oils which differ in their chemical composition (Jowitt, 1908; Guenther, 1940; Guenther, 1950; Senaratne, 1956). The Sri Lankan species, Cymbopogon nardus (L) Rendle is cultivated almost exclusively in Sri Lanka. The Java species, Cymbopogon winterianus Jowitt, although originated in Sri Lanka (Guenther, 1950), is cultivated chiefly on the islands of Java and Formosa.

Cymbopogon winterianus, is less hardy than Cymbopogon nardus and requires more fertile soil. Though, $C$. winterianus gives a higher yield of oil which is of better quality than C. nardus (Brown \& Mathews, 1951), latter is cultivated commercially in Sri Lanka for over a century, because there is a belief among native citronella oil producers that this crop does not require much fertilizers and attention. In spite of the fact that citronella is a soilexhausting crop, plantations are not generally manured (Brown \& Mathews, 1951). Some oil producers in Sri Lanka use the spent grass or its ash obtained after distillation of oil as fertilizer for this crop.

* Corresponding Author 
The variability of the chemical composition of oils observed within Cymbopogon nardus species indicates the availability of many strains with genetic difference (Iruthayathas et al, 1977). A mixture of these strains are grown in commercial plantations in Sri Lanka.

Very few reports are available on the fertilizer studies of this crop. Fertilizer studies conducted in Sri Lanka (Joachim \& Pandittasekera, 1953) and in India (Chandra, 1972), have shown that citronella oil yield was increased due to application of NPK fertilizers. The involvement of phosphorus and magnesium in terpene biosynthesis has been reported (Hanson, 1967). However, no recorded information is available on effects of magnesium and phosphorus on the growth of Cymbopogon nardus and the yield of its essential oil. Therefore, this research was initiated to examine the effects of magnesium and phosphorus nutrition on growth and the essential oil yield of Cymbopogon nardus.

\section{Materials and Methods}

\section{Experimental Procedure:}

Soil culture pot experiment with thirteen fertilizer treatments (Table 2) and 8 replications was conducted in 1990 under greenhouse conditions at the University of Sri Jayewardenepura, Sri Lanka. A complete randomized block design was used.

Table 1. Characteristics of soil used in experiment.

1) $\mathrm{pH}$

$-\quad 5.1$

2) $0.1 \mathrm{~N} \mathrm{H}_{2} \mathrm{SO}_{4}$ Extractable $\mathrm{P}$, $\left(\mathrm{mgP}_{2} \mathrm{O}_{5} / 100 \mathrm{~g}\right.$ soil) $\quad$ - 5.7

3) Exchangeable cations:

(mg/100g soil)

Calcium

$-120.4$

Magnesium

$-\quad 10.0$

Pottasium

$-\quad 13.2$

4) Organic C

$-\quad 0.92 \%$

5) Total nitrogen

$-\quad 0.11 \%$ 
Yellow podsol soil with low phosphorus and magnesium content as descsibed in Table 1, was used in this experiment. The surface soil of $20 \mathrm{~cm}$. was air dried, sieved and mixed with approp:iate fertliizers according to different fertilizer treatments as indicated in Table 2. All treatments were given a basal application of urea $(0.52 \mathrm{~g} / \mathrm{Kg}$ soil) and muriate of potash $(0.33 \mathrm{~g} / \mathrm{Kg}$ soil $)$ before planting. Each pot was filed with $3 \mathrm{~kg}$ of soil.

Table 2. Tiller number, phosphorus uptake and dry matter yield of Cymbopogon nardus as affected by $\mathbf{P}$ and $\mathbf{M g}$ Nutrition

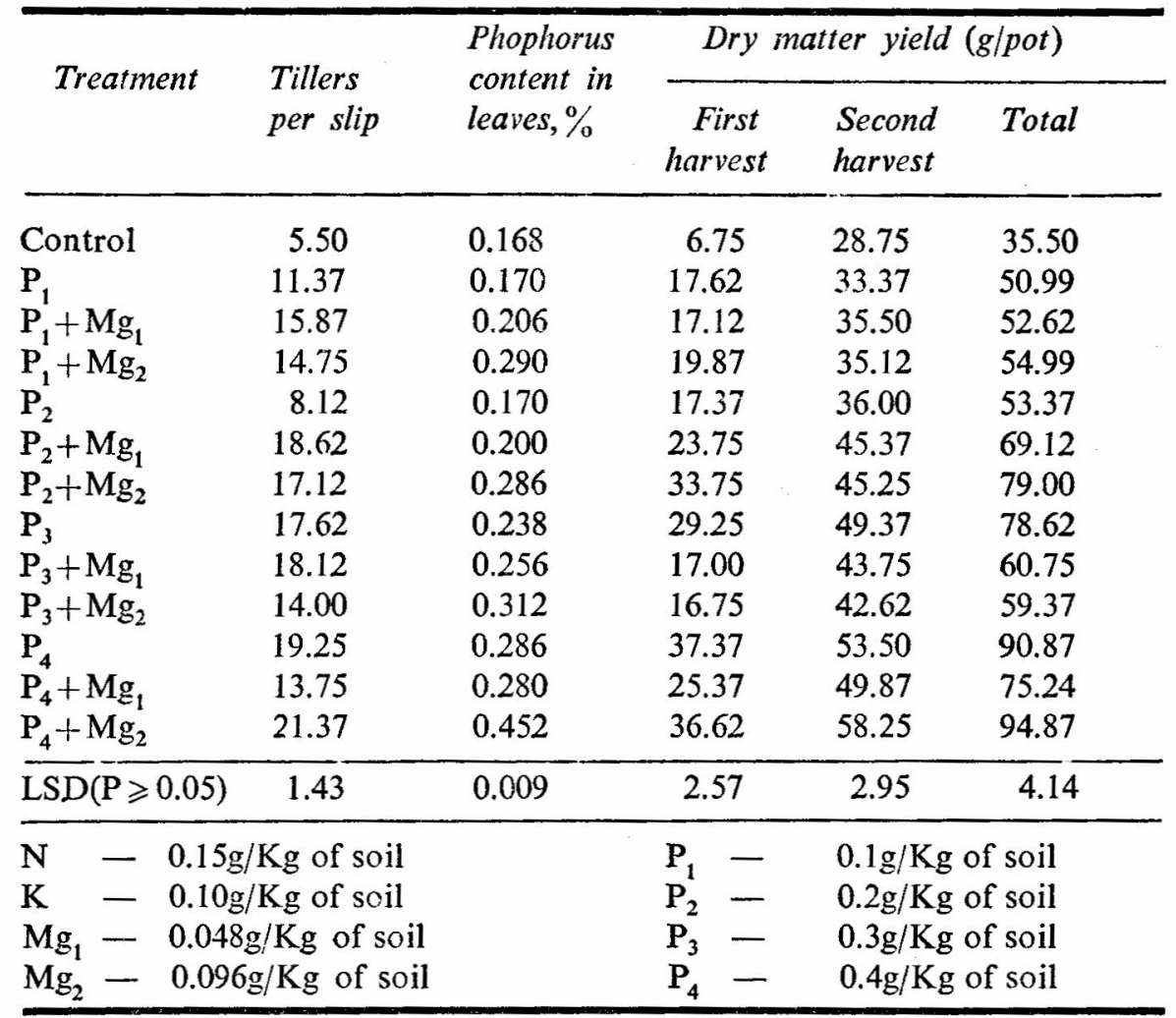

Planting material of Cymbopogon nardus was obtained from a citronella plantation at Walasmulla, from the southern part of Sri Lanka. Pots were planted with two slips of $C$. nadus and later thinned down to one. Pots were watered daily.

The crop was harvested twice. The first harvest was made after four months and the second harvest after seven months of planting. For harvesting, the above ground part was cut and the fresh weight and the dry weight were determined. A top dressing of urea at the rate of $1.0 \mathrm{~g} /$ pot was supplied after the first harvest. Number of tillers produced also was counted at the time of harvest. 
Analytical method: :

A soil suspension prepared with $1 \mathrm{~N} \mathrm{KCI}(1: 2.5)$ was used for soil pH determination. For the determination of available phosphorus, soil was extracted with $0.1 \mathrm{~N} \mathrm{H}_{2} \mathrm{SO}_{4}$ and phosphorus was determined by Truorg-Mayer method (Peterburski, 1968). Exchangeable calcium and magnesium in soil were determined by EDTA titration (Heses, 1971) after extraction with IN ammonium acetate solution $(\mathrm{pH}, 7)$.

Harvested leaves were dryed at $70^{\circ} \mathrm{C}$ in an oven and ashed in a Muffle furnace at $525^{\circ} \mathrm{C}$ and subsequently the total phosphorus content was determined colorimetrically by vanadomolybdate procedure (Peterburski, 1968).

The essential oil content was determined by steam distillation of leaves using a Clevanger distillation apparatus and the oil content was expressed in Clevanger units (Brain and Turner, 1975).

\section{Statistical methods:}

Data were analysed by ANOVA method, at the $5 \%$ level of significance. For regression analysis data were fitted to various non-linear regression models with the aid of MINITAB statistical computer program.

\section{Results}

Results on the growth performance and phosphorus uptake of Cymbopogon nardus as affected by phosphorus and magnesium nutrition are presented in Table 2.

As observed in Table 2, the application of phosphorus has significantly increased the number of tillers per slip. Number of tillers was increased due to application of $P_{1}$ and $P_{4}$ from 5.5 in the control to 11.37 and 19.25 respectively. Though the magnesium nutrition did not show much effect on tiller production, fertilizer combination $\mathrm{P}_{4}+\mathrm{Mg}_{2}$ gave the highest number of tillers. This increase was $11 \%$ over the $P_{4}$ level. The positive relationship between the number of tillers per slip and the phosphorus content in leaves $(r=+0.66)$ is described by the regression equation, $\mathrm{Y}=424-689 \mathrm{x}+387 \log \mathrm{x}$, at $\mathrm{P}<0.001$ (Fig. 1.) 


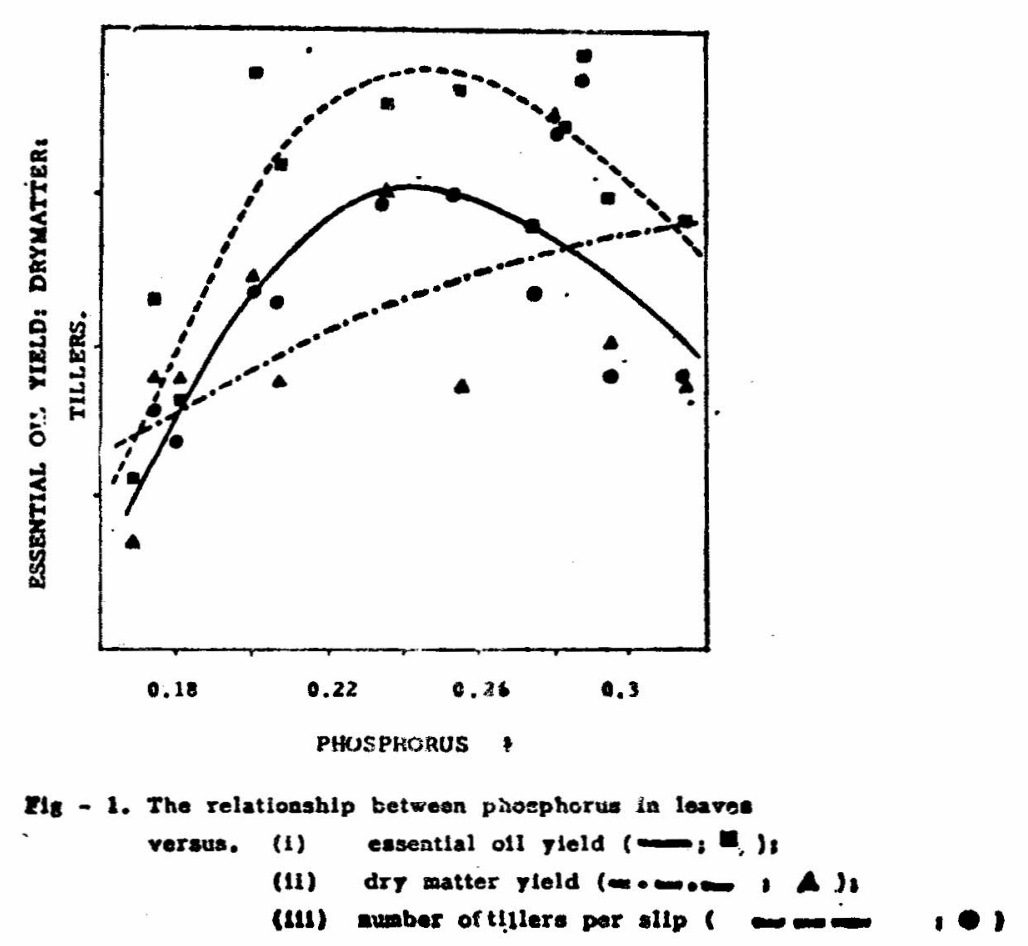

At both harvests, dry matter yield was significantly increased due to application of all levels of phosphorus fertilizers (Table 2). At the first harvest, $P_{1}$ and $P_{4}$ phosphorus levels had increased the dry matter yield from $6.75 \mathrm{~g}$ in the control to 17.62 and $37.37 \mathrm{~g}$ per plant respectively. Application of magnesium in combination with phosphorus fertilizers has produced a better yield of dry matter than that with phosphorus alone. Figure 1. indicates that the dry matter accumulation was also well correlated with the phosphorus contents in leaves $(r=+0.65)$ as described by the regression equation, $Y=67.8$ $-25 \mathrm{x}+63.1 \log \mathrm{x}$, at $\mathrm{P}<0.054$.

The phosphorus content in leaves also was significantly increased by the addition of phosphorus and magnesium fertilizers (Table 2). The application of $P_{3}$ and $P_{4}$ have increased the phosphorus content in leaves to $0.24 \%$ and $0.29 \%$ respectively from $0.16 \%$ in control without phosphorus fertilizers. A higher uptake of phosphorus was observed when magnesium was applied in combination with all levels of phosphorus. 
Table-3. Essential oil yield of Cymbopogon nardus, as affected by $\mathbf{P}$ and $\mathbf{M g}$ nutrition.

\begin{tabular}{lccc}
\hline & \multicolumn{3}{c}{ Essential oil yield $(*$ Clevenger units) } \\
\cline { 2 - 4 } Treatment & $\begin{array}{l}\text { First } \\
\text { harvest }\end{array}$ & $\begin{array}{l}\text { Second } \\
\text { harvest }\end{array}$ & Total \\
\hline Control & 3.50 & 11.12 & 14.62 \\
$\mathrm{P}_{1}$ & 7.50 & 22.50 & 30.00 \\
$\mathrm{P}_{1}+\mathrm{Mg}_{1}$ & 11.12 & 14.62 & 25.74 \\
$\mathrm{P}_{1}+\mathrm{Mg}_{2}$ & 8.87 & 17.37 & 26.24 \\
$\mathrm{P}_{2}$ & 6.50 & 20.25 & 26.75 \\
$\mathrm{P}_{2}+\mathrm{Mg}_{1}$ & 11.50 & 21.62 & 33.12 \\
$\mathrm{P}_{2}+\mathrm{Mg}_{2}$ & 16.00 & 21.00 & 37.00 \\
$\mathrm{P}_{3}$ & 14.37 & 23.00 & 37.37 \\
$\mathrm{P}_{3}+\mathrm{Mg}_{1}$ & 14.62 & 22.50 & 37.12 \\
$\mathrm{P}_{3}+\mathrm{Mg}_{2}$ & 8.75 & 17.75 & 26.50 \\
$\mathrm{P}_{4}$ & 18.00 & 20.50 & 38.50 \\
$\mathrm{P}_{\mathrm{s}}+\mathrm{Mg}_{1}$ & 11.62 & 25.87 & 37.49 \\
$\mathrm{P}_{4}+\mathrm{Mg}_{2}$ & 19.12 & 29.37 & 48.89 \\
\hline $\mathrm{LSD}(\mathrm{P} \geqslant 0.05)$ & 1.43 & 1.51 & 2.32 \\
\hline$(100 \mathrm{Clevenger}$ units $=3.84 \mathrm{ml})$ & & \\
\hline
\end{tabular}

From the Table 3, it is clear that the phosphorus and magnesium nutrition had a significant effect on the essential oil yield both at first and second harvests. The phosphorus level $\left(\mathrm{P}_{1}\right)$ increased the total oil yield by $105 \%$ over the control. Application of $\mathrm{P}_{3}$ and $\mathrm{P}_{4}$ increased the oil production from 30.0 in $\mathrm{P}_{1}$ to 37.37 and 38.5 Cleyanger units (C.u.) respectively. When magnesium $\left(\mathrm{Mg}_{1}\right.$ and $\left.\mathrm{Mg}_{2}\right)$ was applied together with $P_{1}$ the essential oil yield was increased from 26.75 in $\mathrm{P} 1$ to 33.12 and $37.0 \mathrm{C}$.u. respectively. The highest essential oil yield of 48.89 C.u. was observed in the fertilizer treatment $\mathbf{P}_{4}+\mathrm{Mg}_{2}$. As shown in Figure 1, a high positive correlation $(r=+0.7)$ has been observed between the essential oil yield and the phosphorus content in leaves and has been described by the regression equation, $Y=-283-1245 x+1238 x^{2}$, at $P<0.005$.

\section{Discussion}

Out results have indicated that the number of tillers per plant and the herbage yield of citronella were increased due to application of phosphorus fertilizers. Similar effects have been observed earlier by other workers (Joachim \& Pandittasekera, 1953; Chandra, 1972). Magnesium nutrition in combination with phosphorus fertilizers had promoted the accumulation of dry matter and tiller production. 
Magnesium nutrition had also enhanced the uptake of phosphorus by citronella (Table 2). This tendancy has been observed previously by other workers with tomatoes (Billy, 1969) and soybeans (Ranaweera \& Threshov, 1977b). It has also been reported that magnesium ions not only enhanced the uptake of phosphorus by soybean plants and also have fascilitated the conversion of mineral phosphorus into organic phosphorus compounds in the plant (Ranaweera \& Threshov, 1977a).

From our results on essential oil production, it is clearly observed that phosphorus nutrition had a positive effect on the formation of essential oils As shown in Fig.1, a high positive correlation $(r=+0.7)$ was observed between the phosphorus content in leaves and the essential oil yield. A positive effect of phosphorus nutrition on the essential oil production of Cymbopogon winterianus and Cymbopogon nardus (Joachim \& Pandittasekesa, 1953; Chandra, 1972) has been reported. In our experiment magnesium had enhanced the effect of phosphorus on the oil production. This positive effect of phosphorus and magnesium nutrition on the essential oil production of citronella could be explained by the involvement of these ions in the biosynthesis of essential oils. Several phosphorylation steps of precurssor compounds are involved in the essential oil biosynthesis and they are shown to be dependant upon adenosine triphosphate (ATP), reduced pyridine nucleotides and magnesium ions (Hanson, 1967).

The optimum concentrations of phosphorus in leaves that produced maximum yields of oil were found to be in the range of $0.23-0.26 \%$, at the first harvest, four months after planting.

At present the citronella growers in Sri Lanka are not getting the expected yields of citronella oil due to the fact that their plantations are generally not manured. Proper application of fertilizers for this crop can improve the yields of essential oil and its quality. It is clear from our experimental results that the phosphorus and magnesium nutrition is effective on the essential oil production by Cymbopogon nurdus. Therefore, further extensive experimentation is needed, to find the effect of these fertilizers on the yield and quality of oil in order to recommend optimum fertilizer dozes for the effective cultivation of this crop.

\section{Acknowledgement}

This study was supported by a grant from the University of Sri Jayewardenepura (USJ). Dr. N. Salim of Department of Botany, USJ is gratefully acknowledged for helpful comments. 


\section{References}

1. Billy, W.H., 1969. Magnesium - Phosphorus Interrelationship in Tomatoes. Agronomy J., 61 (3) 34-39.

2. Brain, K.R. and T.D. Turner, 1975. Determination of Essential Oil Content: The Practical Evaluation of Phytopharmaceuticals Bristol, Wright-Scientechnica, 86-87.

3. Brown, E. and W.S.A. Mathews, 1951. Notes on the Aromatic Grasses of Commercial Importance. Colonial Plants and Animal Products, 2 : 178-181.

4. Chandra, V., 1972. Effect of Varying Concentration of N.P.K. Fertilizer on yield and oil of Cymbopogon winterianus Jowitt. Indian Perfumer, 16 (1): 52-56.

5. Guenther, E., 1940. Ceylon Citronella. Soap Sanitary Chemistry, 16 (10) : 32-37.

6. Guenther, E., 1950. The Essential Oils. New York, Van Nostrand 4 : 67.

7. Heses, P.R., 1971. A textbook of soil chemical analysis, London; John murray.

8. Hanson, J.R., 1967. The Biosynthesis of the Monoterpenes. Perfum. and Ess. Oil Res., Nov. 787-795.

9. Iruthayathas, E.E., H.M.W.Herath, R.O.B.Wi jesekera, and A.L.Jayawardene, 1977. Variation in the Composition of Oil in Citronella. J. Natn. Sci. Coun. Sri Lanka, 5 (2) : 133-146.

10. Joachim, A.W.R. and D.G.Pandittasekera, 1953. Investigations on the Cultivation of Citronella in Ceylon: Part I - The Effects of Organic and Artificial Fertilizers on the Yield of Grass and Oil. The Tropical Agriculturist, 109 (3): 1-11.

11. Jowitt, J.F., 1908. The Volatile Oils (Gildemeister, A. and Hoffman, A. eds., Kremere, E., transl.), 2nd Edn., 2:217-243, Annals Royal Botaanical Gardens, Peradeniya $41: 185$.

12. Peterburski, A.V., 1968. Determination of Available Phosphorus in Kraznoseom soils. Prakticum po Agronomicheskoi Chemie, 6th Edn., Mockva, Isdatelstvo "Kolos."

13. Ranwecra, S.S. and A.G.Threshov, 1977a. The effects of magnesium and Phosphorus Nutrition on the Fractional Composition of Magnesium and Phosphorus in Soybean Plant. Problemie Tropicheskoi i Subtropicheskoi Kulturie, 136 (10) : 3-7.

14. Ranaweera, S.S. and A.G. Threshov, 1977b. Effects of Different Levels of $\mathrm{Mg}$ and $\mathbf{P}$ Nutrition on the Uptake of Nutrient Elements by the Soybean Plant. Problemie Trcpicheskoi i Subtropicheskoi Kulturie, 136 (10): 91-95.

15. Senaratne, J.E., 1956. The Grasses cf Ceylon, Peradeniya Manual, Government Press Colombo, Ceylon, 8 : 193. 